CLINICAL STUDY

\title{
Adaptation of ghrelin and the GH/IGF axis to high altitude
}

\author{
Stefan Riedl, Michael Kluge ${ }^{1}$, Katharina Schweitzer ${ }^{2}$, Thomas Waldhör ${ }^{3}$ and Herwig Frisch \\ Pediatric Department, St Anna Children's Hospital, Medical University of Vienna, Kinderspitalgasse 6, A-1090 Vienna, Austria, ${ }^{1}$ Department of \\ Psychiatry, University of Leipzig, Semmelweissstrasse 10, 04103 Leipzig, Germany, ${ }^{2}$ Pediatric Department, Medical University of Vienna, Währinger \\ Gürtel 18-20, 1090 Vienna, Austria and ${ }^{3}$ Department of Epidemiology, Centre of Public Health, Medical University of Vienna, Borschkegasse 8a, \\ 1090 Vienna, Austria
}

(Correspondence should be addressed to S Riedl; Email: stefan.riedl@meduniwien.ac.at)

\begin{abstract}
Objective: High altitude (HA) provokes a variety of endocrine adaptive processes. We investigated the impact of HA on ghrelin levels and the GH/IGF axis.

Design: Observational study as part of a medical multidisciplinary project in a mountainous environment.

Methods: Thirty-three probands (12 females) were investigated at three timepoints during ascent to HA (A: d -42, $120 \mathrm{~m}$; B: d +4, $3440 \mathrm{~m}$; C: d + 14, $5050 \mathrm{~m}$ ). The following parameters were obtained: ghrelin; GH; GH-binding protein (GHBP); IGF1; IGF2; IGF-binding proteins (IGFBPs) -1, -2, and -3; acid-labile subunit (ALS); and insulin. Weight was monitored and general well being assessed using the Lake Louise acute mountain sickness (AMS) score.

Results: Ghrelin (150 vs $111 \mathrm{pg} / \mathrm{ml} ; P<0.01$ ) and GH (3.4 vs $1.7 \mu \mathrm{g} / \mathrm{l} ; P<0.01$ ) were significantly higher at timepoint $C$ compared with A whereas GHBP, IGF1, IGF2, IGFBP3, ALS, and insulin levels did not change. IGFBP1 (58 vs $47 \mu \mathrm{g} / \mathrm{l} ; P<0.05$ ) and, even more pronounced, IGFBP2 (1141 vs $615 \mu \mathrm{g} / \mathrm{l}$; $P<0.001)$ increased significantly. No correlation, neither sex-specific nor in the total group, between individual weight loss (females: $-2.1 \mathrm{~kg}$; males: $-5.1 \mathrm{~kg}$ ) and rise in ghrelin was found. Five of the subjects did not reach investigation point $\mathrm{C}$ due to AMS.

Conclusions: After 14 days of exposure to HA, we observed a significant ghrelin and GH increase without changes in GHBP, IGF1, IGF2, IGFBP3, ALS, and insulin. Higher GH seems to be needed for acute metabolic effects rather than IGF/IGFBP3 generation. Increased IGFBP1 and -2 may reflect effects from HA on IGF bioavailability.
\end{abstract}

European Journal of Endocrinology 166 969-976

\section{Introduction}

Adaptation to high altitude (HA) involves complex changes in metabolic and endocrine functions. According to its central role in regulation of substrate metabolism and anabolism, the GH axis under increased physical stress deserves specific consideration.

GH secretion is regulated by GHRH whose effects are opposed by somatostatin and diverse GH-releasing peptides, so-called GH secretagogues. Ghrelin seems to play a central role in $\mathrm{GH}$ regulation as well as in central energy balance, increasing appetite, food intake, and lipogenesis, hence promoting a positive energy balance $(1,2)$. Ghrelin acts on GH release both via direct stimulation and via promoting GHRH stimulation $(3,4)$.

GH is bound to GH-binding protein (GHBP) in plasma and exerts its effects both directly and via insulin-like growth factor (IGF) -1 generation. Apart from absolute IGF1 levels regulated by GH, levels of free unbound IGF, i.e. IGF1 bioavailability, depend on their interplay with IGF-binding proteins (IGFBP). The fraction of free IGF1 in the circulation lies under $1 \%$ whereas $99 \%$ is bound to IGFBPs, mainly IGFBP3, forming a ternary complex with acid-labile subunit (ALS). While IGF/IGFBP3/ALS complexes represent a stable IGF reservoir in plasma, IGF 1 is more easily released from binary complexes with IGFBP1 and $-2(5,6)$, the latter having specific affinity for IGF2 (7). Hence, alterations of these binding proteins play an important role in fine-tuning IGF bioavailability and may be needed to protect the organism from hypoglycemia $(8,9)$. In addition, decreased IGF bioavailability may serve to redirect energy resources toward essential metabolic processes under conditions of limited substrate supply (10).

Studies performed at HA or under hypobaric/hypoxic conditions simulating HA have revealed conflicting results as study designs are rarely comparable regarding altitude, time of exposure to HA, number of subjects, and individual training status. In addition, metabolic adaptations at HA may be influenced by weight loss, which is a well-known consequence depending on duration of 
exposure and the altitude reached, hence the magnitude of altitude hypoxia. It is assumed to result from complex interactions between decreased food intake, increase of the basal metabolic rate, negative energy balance, impaired intestinal function, changes in body composition, and loss of body water (11).

Ghrelin plasma levels are inversely correlated with weight: weight loss leads to an increase in ghrelin plasma levels, whereas weight gain leads to a decrease (2). Accordingly, an increase in ghrelin levels associated with weight loss during exposure to HA would be expected. However, two studies investigating ghrelin adaptation to HA found a 30\% decrease in ghrelin plasma levels in 30 lowlanders $48 \mathrm{~h}$ after being taken to $4300 \mathrm{~m} \mathrm{(12),} \mathrm{and} \mathrm{unchanged} \mathrm{ghrelin} \mathrm{levels} \mathrm{among}$ nine elite climbers after exposure to very HA respectively (13). Hence, as weight loss is an inevitable consequence from ascent to HA, it may be difficult to discriminate between secondary effects due to weight loss and direct change of endocrine regulation, e.g. by hypobaric hypoxia. Impedingly, exposure to an extreme condition such as very HA has a limiting effect on the experimental design. Elimination of confounding factors like interindividual caloric intake or different physical activity would be desirable but is hardly feasible.

We performed a comprehensive study on the $\mathrm{GH}$ axis in a group of 33 volunteers during ascent to very HA. Analyzed parameters comprised ghrelin, GH, GHBP, IGF1, IGF2, IGFBP1, -2, -3, ALS, and insulin. We hypothesized that during ascent to HA, ghrelin levels would increase with potential effects on GH release to compensate for higher energy demands. In addition, we expected specific changes in IGFs and IGFBPs with a possible impact on IGF bioavailability.

\section{Materials and methods}

Thirty-three Caucasians (12 females (median age 38.9 years (23-48); height $168.1 \pm 5.1 \mathrm{~cm}$; weight 63.4 $\pm 8.3 \mathrm{~kg}$ ) and 21 males (median age 43.4 years (19-65); height $180.1 \pm 5.1 \mathrm{~cm}$; weight 77.9 $\pm 7.0 \mathrm{~kg}$ )) took part in the study. None of them was an athlete, but all were healthy and in a good physical condition. One out of 12 female (body mass index (BMI) $28.2 \mathrm{~kg} / \mathrm{m}^{2}$ ) and $6 / 21$ male subjects (BMI $26.2-27.7 \mathrm{~kg} / \mathrm{m}^{2}$ ) were overweight $\left(\mathrm{BMI}>25 \mathrm{~kg} / \mathrm{m}^{2}\right)$, but none of them was obese. Exclusion criteria comprised a stay at HA during the last 6 months and any medication. All probands gave their written informed consent. The protocol was approved by the ethics committee of the Medical University of Vienna.

\section{Study description}

Medical research teams from several sub-specialities took part in the study, which was designed to explore various aspects of HA medicine. Results from this study on melatonin, adrenomedullin, and brain natriuretic peptide changes at HA have already been published $(14,15,16)$.

Baseline investigations (A) were performed at $120 \mathrm{~m}$ above sea level (SL) (Herxheim, Germany). Six weeks later, the subjects went to an altitude of $1400 \mathrm{~m}$ (Kathmandu, Nepal). To obtain two groups of the same size, subjects were assigned to either the trekking team (TT, $n=17$ ) or the climbing team (CT, $n=16)$, taking into account the individual level of physical fitness and personal preference. Gender distribution showed a preponderance of females in the TT (8/17) compared with the CT (4/16) and a higher median age in TT (median age 43 years; range 19-65 years) vs CT (median age 35.5 years; range 23-63 years). BMI was similar in both groups (mean BMI $23.2 \pm 2.5 \mathrm{~kg} / \mathrm{m}^{2}$ in TT; mean BMI $23.6 \pm 2.2 \mathrm{~kg} / \mathrm{m}^{2}$ in CT). Three out of seven overweight subjects with BMI $>25 \mathrm{~kg} / \mathrm{m}^{2}$ were in the TT and $4 / 7$ in the CT groups. They were airlifted to an altitude of $2840 \mathrm{~m}$ (Lukla, Nepal), with the CT starting 1 day earlier. The further ascent was by foot. On day 4 , investigation $\mathrm{B}$ was performed at an altitude of 3440 m (Namche Bazaar, Nepal). During the following days, the TT hiked along the Gokyo valley, whereas the CT attempted to climb the Island peak. Daily physical activity was moderate at $6-8 \mathrm{~h}$. TT and CT did not differ concerning overnight altitudes (Fig. 1), only with regard to maximal altitudes reached (TT $5050 \mathrm{~m}$; CT 5400-5900 m). Nine days later, both teams arrived at the 'Silver Pyramid' (Italian-Nepalesian Research Center Ev-K2-CNR, Lobuche, $5050 \mathrm{~m}$ ) where investigation $\mathrm{C}$ was performed (day 14).

Time in bed lasted from $2200 \mathrm{~h}$ until $0600 \mathrm{~h}$. After a phase of acclimatization lasting for $\sim 1$ week, participants reported satisfactory sleep quality. Due to altitude

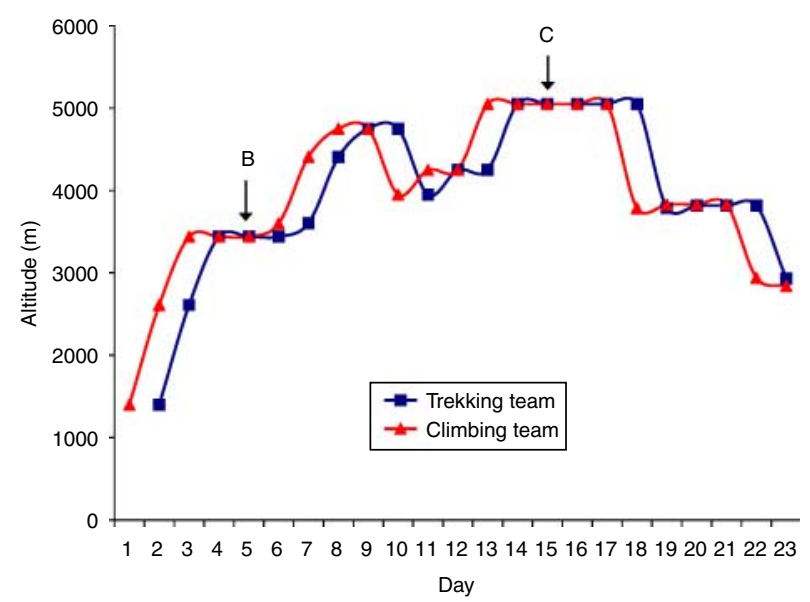

Figure 1 Profile of overnight altitudes of the trekking team and the climbing team during the expedition. Vertical arrows indicate investigation timepoints $B($ day $+4 ; 3440 \mathrm{~m}$ ) and $C$ (day +14 ; $5050 \mathrm{~m}$ ). Full colour version of this figure available via http://dx.doi. org/10.1530/EJE-12-0007. 
diuresis, each subject had to get up two to three times per night.

Food intake was analyzed on the basis of dietary recall protocols over 2 days. A typical diet, based on average portion sizes (females $\times 1$; males $\times 1.25$ ) and ad libitum fluid intake, provided $\sim 2780 \mathrm{kcal} /$ day in females and $\sim 3480 \mathrm{kcal} /$ day in males. Protein content was $\sim 13 \%$, fat $\sim 27 \%$, and carbohydrate $\sim 60 \%$.

Investigations were performed $36 \mathrm{~h}$ after arrival at medium/HA, allowing 1 day for resting without physical exertion or altitude change. Fasting venous blood samples were taken in the morning between 0600 and $0700 \mathrm{~h}$ (12 $\mathrm{h}$ after dinner) in a sitting position after a resting period of at least $15 \mathrm{~min}$. Serum was separated immediately by centrifugation and stored frozen $\left(-20{ }^{\circ} \mathrm{C}\right)$ until analysis within 3 months.

The following parameters were evaluated: ghrelin, GH, GHBP, IGF1, IGF2, IGFBP1, IGFBP2, IGFBP3, ALS, and insulin. General well being was monitored daily using the Lake Louise acute mountain sickness (AMS) score. This self-assessment questionnaire for early detection of AMS estimates the degree $(0-3 ; 0=$ none; $3=$ severe) of headache, appetite/nausea, weakness, dizziness, sleeping problems, and overall effect on activities, considering a score $\geq 3$ as positive (17).

Apart from body weight, the probands' urinary output, urinary osmolality, hematocrit, protein, and lactate levels were measured to monitor hemoconcentration and alterations of aerobic/anaerobic metabolism.

\section{Biochemical analysis}

Plasma immunoreactive ghrelin was measured using an iodine-125-labeled bioactive ghrelin tracer and a rabbit polyclonal antibody raised against full-length octanoylated human ghrelin, showing 100\% crossreactivity with des-acyl ghrelin (Peninsula Laboratories, Inc., Belmont, CA, USA). The lower and upper limits of the assay were 20 and $2000 \mathrm{pg} / \mathrm{ml}$ respectively. The intra- and interassay coefficients of variation (CV) were 4.1 and $12.0 \%$ respectively.

Serum GH was determined by IRMA using two MABs, one of which was labeled with iodine-125 (Biochem Immunosystems, Guidonia Montecelio, Roma, Italy). The sensitivity of the assay was $0.07 \mu \mathrm{g} / \mathrm{l}$, and the intraassay and interassay $C V$ were 5 and $4.5 \%$ respectively.

GHBP was measured using an iodine-125-labeled GHBP tracer and a rabbit polyclonal antibody according to Blum et al. (18). Inter- and intra-assay CV were 11.1 and $5 \%$ respectively.

IGF1 was determined using an iodine-125-labeled IGF1 tracer and a specific polyclonal antibody as described before (19). Serum samples were extracted by acid-ethanol and diluted 1:20 before assay. The intra-assay $\mathrm{CV}$ was $11.8 \%$ and the interassay $\mathrm{CV}$ was $12 \%$.
For IGF2 determination, a coated-tube IRMA was used (DSL-9100; Diagnostic System Laboratories, Webster, TX, USA). Sensitivity was $12 \mathrm{ng} / \mathrm{ml}$, the intra-assay and interassay CV were 7 and $10 \%$ respectively.

IGFBP1 was measured by ELISA (DSL-10-7800, Diagnostic System Laboratories). Sensitivity was $0.25 \mathrm{ng} / \mathrm{ml}$ and the intra-assay and interassay $\mathrm{CV}$ were 5 and $8 \%$ respectively.

IGFBP 2 concentrations were determined by a doubleantibody RIA kit (DSL 7100; Diagnostic System Laboratories). Intra-assay and interassay $\mathrm{CV}$ were 9 and $7 \%$ respectively.

IGFBP3 levels were analyzed by RIA (Mediagnost, Tübingen, Germany). The sensitivity of the assay was $0.06 \mu \mathrm{g} / \mathrm{l}$. The intra- and interassay $\mathrm{CV}$ were 8.5 and $11 \%$ respectively.

ALS was determined by ELISA (DSL-10-8200; Diagnostic System Laboratories). Minimal detection limit was $0.07 \mu \mathrm{g} / \mathrm{ml}$. The intra- and interassay $\mathrm{CV}$ were 6 and $9 \%$ respectively.

Insulin was measured with an automated immunochemiluminometric (ICL) assay (ADVIA Centaur insulin assay; Bayer Diagnostics). Sensitivity was $3.6 \mathrm{pmol} / \mathrm{l}$ $(0.5 \mathrm{mIU} / \mathrm{l})$. The intra- and interassay $\mathrm{CV}$ were 4.7 and $5.3 \%$ respectively.

For all commercial ELISA, RIA, IRMA, and ICL methods used, the procedures for the assays were followed as specified by the supplier. Each proband's samples were measured in duplicates in the same assay.

\section{Statistical analysis}

For comparison between groups, the unpaired $t$-test was used. Comparison within groups, i.e. individual subjects at timepoints $\mathrm{A}, \mathrm{B}$, and $\mathrm{C}$, was done by paired $t$-test (B vs A; C vs A; C vs B). A subanalysis was performed to look for sex-specific differences, comparing females and males at different timepoints. In order to take into account the multiple testing scenarios, $P$ values were adjusted for multiple testing by false discovery rate method using 'proc multtest', SAS version 9.2 (SAS Institute, Inc., Cary, NC, USA).

Associations between changes in different parameters at timepoints A and C were tested by Spearman's correlation coefficient. The corresponding changes were calculated by dividing the value observed at timepoint $\mathrm{A}$ by the value at timepoint $\mathrm{C}$.

\section{Results}

\section{General well being/AMS score}

Characteristics of the study population are presented in Table 1. All 33 probands reached investigation timepoint B at $3440 \mathrm{~m}$. Four days later, five subjects from the TT ( 4 females) had to return because of AMS 
Table 1 Characteristics of the probands. Age (median (range)), height, BMI, and weight before (timepoint A) and after (timepoint C) ascent to very HA (mean \pm s.D.).

\begin{tabular}{lcc}
\hline & \multicolumn{2}{c}{ All, $n=33$} \\
\cline { 2 - 3 } & Female, $n=12$ & Male, $n=21$ \\
\hline Age (years) & $38.9(23-48)$ & $43.4(19-65)$ \\
Height $(\mathrm{cm})$ & $168.1 \pm 5.1$ & $180.1 \pm 5.1$ \\
BMl $\left(\mathrm{kg} / \mathrm{m}^{2}\right)$ & $24 \pm 2.3$ & $22.3 \pm 2.2$ \\
Weight $(\mathrm{kg})$ & & \\
A (day -42$), 120 \mathrm{~m}$ & $63.4 \pm 8.3$ & $77.9 \pm 7.0$ \\
C (day +14$), 5050 \mathrm{~m}$ & $61.3 \pm 7.8^{\star}(-3.3 \%)$ & $72.8 \pm 6.7^{\star}(-6.5 \%)$ \\
\hline
\end{tabular}

${ }^{*} P<0.01 ; \mathrm{C}$ vs $\mathrm{A}$. BMI, body mass index.

symptoms (AMS score $\geq 3$ ) and could not be investigated at timepoint $\mathrm{C}$.

\section{Effects of HA on weight, hemoconcentration parameters, and lactate}

A significant weight loss (overall $-4.3 \pm 1.9 \mathrm{~kg} ;-5.8 \%$ ) occurred during the study period: mean weight at timepoint $\mathrm{C}$ was $61.3 \pm 7.8 \mathrm{~kg}$ in females $(-2.1 \pm 1.5 \mathrm{~kg}$ or $-3.3 \%$ compared with $\mathrm{A}$ ) and $72.8 \pm 6.7 \mathrm{~kg}$ in males $(-5.1 \pm 1.5 \mathrm{~kg}$ or $-6.5 \%$ compared with A; Table 1$)$. One out of eight female (BMI $27 \mathrm{~kg} / \mathrm{m}^{2}$ ) and $3 / 20$ male subjects (BMI $25.5 \pm 0.2 \mathrm{~kg} / \mathrm{m}^{2}$ ) were still overweight at timepoint $\mathrm{C}$. Urinary output increased, associated with a decrease in urinary osmolality and an increase in plasma protein levels. Hematocrit was stable and lactate levels did not change (Table 2).

\section{Ghrelin and GH levels}

We observed a significant increase in ghrelin $(+35 \%$ vs baseline; $P<0.01)$ and $\mathrm{GH}$ levels $(+100 \%$ vs baseline; $P<0.05)$ at timepoint $C$ (Table 3$)$. On an individual basis, an increase in ghrelin exceeding the intra-assay CV occurred in $68 \%$. Similarly, a GH increase was present in $75 \%$ of the probands. No significant changes were observed for either hormone from baseline to timepoint B. Ghrelin levels in the overweight subjects (timepoint A: $101 \pm 59 \mathrm{pg} / \mathrm{ml}$; timepoint C: 160 $\pm 110 \mathrm{pg} / \mathrm{ml}$ ) were similar compared with the whole group. Separate analysis of ghrelin and GH in both sexes revealed that while males showed a significant increase in ghrelin and $\mathrm{GH}$ at timepoint $\mathrm{C}$ compared with baseline $(P<0.05)$, females did not (Table 4$)$.

\section{Correlation between weight loss and ghrelin}

No correlation between individual weight loss and change in ghrelin levels at timepoint $\mathrm{C}$, neither in the whole group $(r=-0.03 ; P=0.89)$ nor in the female $(r=0.11) /$ male $(r=0.06)$ subgroups, was ascertainable. In addition, no differences were found by analyzing TT $(r=-0.23$; $P=0.47)$ and CT $(r=0.12 ; P=0.69)$ separately.

\section{GHBP, IGF1, IGF2, IGFBP1, IGFBP2, IGFBP3, ALS, and insulin}

A significant rise in IGFBP1 and -2 occurred at timepoint $\mathrm{B} \quad(P<0.01)$ and timepoint $\mathrm{C} \quad(P<0.05$ and $<0.01$ respectively). No significant change in GHBP, IGF1, IGF2, IGFBP3, or ALS was seen (Table 3). IGF1 showed a trend toward decrease at timepoint $\mathrm{C}$ compared with timepoint B $(P=0.067)$. Insulin levels remained unchanged. Correlation analysis revealed significant inverse relationships between insulin and IGFBP1 $(r=-0.56 ; P<0.01)$ as well as between insulin and IGFBP2 $(r=-0.39 ; P<0.05)$, comparing timepoint $\mathrm{C}$ to baseline.

\section{Discussion}

Our study on 33 subjects during ascent to HA revealed a series of conclusive adaptations of the $\mathrm{GH}$ axis associated with physical stress in a hypobaric hypoxic environment: i) an increase in ghrelin, ii) an increase in $\mathrm{GH}$, and iii) an increase in IGFBP1 and -2. GHBP, IGF1, IGF2, IGFBP3, ALS, and insulin levels did not change after 2 weeks of exposure to HA. Still, with regard to the interplay between effector hormones and their binding proteins, changes in bioavailability of the latter have to be assumed.

The expected rise in ghrelin levels promoting a positive energy balance can be explained by known physiological mechanisms. Most importantly, weight loss associated with an anorexic condition has an increasing effect on ghrelin levels. Accordingly, it has been shown that a ghrelin rise occurs before or in the expectation of a meal and that lean subjects have higher ghrelin levels than obese ones $(1,2,20)$. Furthermore, ghrelin is a potent vasodilator and has been shown to play a role in regulation of vascular tone (21). In accordance, studies on rats have demonstrated that exogenous ghrelin attenuates chronic hypoxia-induced pulmonary arterial hypertension and prevents an increase in cardiac sympathetic tone following myocardial infarction $(22,23)$, suggesting a specific role to ameliorate vascular supply by vasodilator effects under hypoxic conditions.

Table 2 Biochemical parameters (mean \pm s.D.) estimating hemoconcentration and aerobic/anaerobic metabolism during ascent to HA.

\begin{tabular}{|c|c|c|c|}
\hline & $\begin{array}{l}\text { A (day }-42) \text {, } \\
120 \mathrm{~m}, n=33\end{array}$ & $\begin{array}{c}\text { B (day }+4), \\
3440 \mathrm{~m}, n=33\end{array}$ & $\begin{array}{c}\text { C (day }+14) \text {, } \\
5050 \mathrm{~m}, n=28\end{array}$ \\
\hline Hematocrit (\%) & $45 \pm 3$ & $44 \pm 4$ & $46 \pm 3$ \\
\hline $\begin{array}{l}\text { Urinary output } \\
\text { (ml/day) }\end{array}$ & $1577 \pm 650$ & $2935 \pm 1231^{\dagger}$ & $3350 \pm 1033^{\dagger}$ \\
\hline $\begin{array}{l}\text { Urinary osmolality } \\
\text { (mOsm } / \mathrm{kg})\end{array}$ & $683 \pm 284$ & $526 \pm 242^{*}$ & $443 \pm 248^{\dagger}$ \\
\hline Protein $(\mathrm{g} / \mathrm{l})$ & $67 \pm 4$ & $69 \pm 4^{\dagger}$ & $71 \pm 4^{\dagger}$ \\
\hline Lactate $(\mathrm{mmol} / \mathrm{l})$ & $2.4 \pm 0.5$ & $2.6 \pm 0.6$ & $2.2 \pm 0.8$ \\
\hline
\end{tabular}

${ }^{\star} P<0.05 ;{ }^{\dagger} P<0.01 ; \mathrm{B}$ vs $\mathrm{A}$ and $\mathrm{C}$ vs $\mathrm{A}$. 
Table 3 Hormonal data (mean \pm s.D.) during the course of ascent to HA.

\begin{tabular}{lccc}
\hline & A (day -42$),$ & B (day +4$),$ & C (day +14$),$ \\
& $120 \mathrm{~m}, n=33$ & $3440 \mathrm{~m}, n=33$ & $5050 \mathrm{~m}, n=28$ \\
\hline Ghrelin $(\mathrm{pg} / \mathrm{ml})$ & $111 \pm 45$ & $119 \pm 57$ & $150 \pm 70^{\dagger}$ \\
GH $(\mu \mathrm{g} / \mathrm{l})$ & $1.7 \pm 3.0$ & $2.1 \pm 3.1$ & $3.4 \pm 3.5^{\dagger}$ \\
GHBP $(\mu \mathrm{g} / \mathrm{l})$ & $2.6 \pm 0.6$ & $2.8 \pm 0.7$ & $2.6 \pm 0.6$ \\
IGF1 $(\mu \mathrm{g} / \mathrm{l})$ & $129 \pm 40$ & $133 \pm 51$ & $121 \pm 43$ \\
IGF2 $(\mu \mathrm{g} / \mathrm{l})$ & $917 \pm 163$ & $848 \pm 139$ & $926 \pm 153$ \\
IGFBP1 $(\mu \mathrm{g} / \mathrm{l})$ & $47 \pm 27$ & $56 \pm 18^{\dagger}$ & $58 \pm 20^{*}$ \\
IGFBP2 $(\mu \mathrm{g} / \mathrm{l})$ & $615 \pm 353$ & $807 \pm 432^{\dagger}$ & $1141 \pm 589^{\dagger}$ \\
IGFBP3 $(\mu \mathrm{g} / \mathrm{l})$ & $4564 \pm 1078$ & $4382 \pm 1154$ & $4296 \pm 1080$ \\
ALS $(\mu \mathrm{g} / \mathrm{ml})$ & $21 \pm 5$ & $20 \pm 4$ & $22 \pm 5$ \\
Insulin (pmol/l) & $43 \pm 13$ & $41 \pm 13$ & $46 \pm 17$ \\
\hline
\end{tabular}

${ }^{*} P<0.05 ;{ }^{\dagger} P<0.01 ; \mathrm{B}$ vs $\mathrm{A}$ and $\mathrm{C}$ vs $\mathrm{A}$.

So far, there are only two comparable studies investigating ghrelin at HA. In contrast to our study, both investigated only males. Shukla et al. (12) studied 30 lowlanders $48 \mathrm{~h}$ after ascent to $4300 \mathrm{~m}$ and found a $30 \%$ decrease in ghrelin levels. However, time of exposure to HA $(4300 \mathrm{~m})$ was limited and baseline investigations were performed at a similar altitude level $(3600 \mathrm{~m})$, which may potentially have had an effect on their findings. Benso et al. (13) investigated a broad spectrum of hormonal parameters in nine elite climbers at $5200 \mathrm{~m}$, shortly after exposure to extreme altitude (7500-8848 m; mean $8615 \mathrm{~m}$ ), compared with SL baseline results. In contrast to their expectation that ghrelin would rise, particularly in view of an average weight loss of $-5 \mathrm{~kg}$, they found no change in ghrelin levels. Nevertheless, individual results in this small group of probands were very heterogeneous. Besides, the critical investigation was performed after expeditious descent (approximately $-3400 \mathrm{~m}$ ) from extreme altitude. It is not clear whether these dynamics of altitude change may have had an additional influence on their results. Body weight reduction without a change in ghrelin levels was also observed in a recent study on 20 male subjects investigated 1 week after exposure to HA (24). However, these subjects were obese (BMI $33.7 \mathrm{~kg} / \mathrm{m}^{2}$ ) and altitude only moderate (2650 m), rendering conclusive comparison difficult.

Former studies investigating $\mathrm{GH}$ at HA have revealed that $\mathrm{GH}$ levels and $\mathrm{GH}$ response to GHRH or exercise rise under hypoxic conditions $(25,26,27)$. We also found a significant increase in GH. It is well known that GH is needed for increased substrate supply and anabolic effects, acting both directly and via IGF1 generation. The rise in ghrelin may be one mechanism to explain the $\mathrm{GH}$ increase in our probands as ghrelin stimulates $\mathrm{GH}$ release directly, by increasing GHRH and by optimizing responsiveness of somatotrophic cells to GHRH (3, 4).

As ghrelin levels are sexually dimorphic (28), we performed a separate analysis of ghrelin and GH looking for sex-specific differences. However, baseline levels were similar, and although there was an overall rise in ghrelin and GH throughout ascent to HA in both sexes, their rise was significant only in males $(n=21)$. The lack of significance in females may have been due to the small number of women who completed the trek $(n=8)$.

Although a significant weight loss and a rise in ghrelin levels occurred in the whole group, no correlation could be observed on an individual level. Thus, it seems that a subject's individual change in ghrelin at HA may be influenced by additional factors such as level of physical exertion or different effects from hypoxia impacting on counter-regulatory hormonal mechanisms.

GHBP constitutes the soluble isoform of the GH receptor and plays a role in regulating bioavailability of $\mathrm{GH}$. When estimating free $\mathrm{GH}$ using ultrafiltration by centrifugation to retain GHBP, Frystyk et al. (29) found a positive correlation between total and free $\mathrm{GH}$ and an inverse relation between free GH and GHBP. In our study population, GHBP levels remained unchanged whereas GH increased significantly. Accordingly, the lack of change in GHBP may have enhanced bioavailable GH.

Former studies, investigating either HA natives or climbers exposed to HA for 2 months, have shown increased IGF1 and IGFBP 3 at HA $(13,26)$. In contrast, studies on short-term effects from exercise under hypoxic conditions revealed either no significant change or a decrease in IGF1 respectively $(25,27)$. In our probands, IGF1 and IGFBP3 levels showed a minor, nonsignificant decrease or remained stable respectively. In addition, ALS did not change. It has been suggested that short-term severe physical stress increases GH secretion, which is used for immediate nutrient supply rather than IGF1 generation (27). Therefore, our findings support the hypothesis that the high energy demands at HA may have overridden effects from elevated GH on IGF1 and IGFBP3 generation.

Nevertheless, it has to be considered that total serum IGF1 levels do not reflect their bioavailability that is finetuned in a complex interplay of different IGFBPs. In our probands, both IGFBP1 and, even more pronounced, IGFBP 2 showed a significant increase during ascent to HA. Physiologically, IGFBP1 and IGFBP2 have been found to counteract insulin effects by decreasing IGF bioavailability and hence insulin-like IGF actions that would promote hypoglycemia $(8,9)$. Both IGFBPs show a negative correlation with insulin, IGFBP1 playing a

Table 4 Sex-specific changes of ghrelin and GH levels (mean \pm S.D.).

\begin{tabular}{lccc}
\hline & $\begin{array}{c}\text { A (day -42), } \\
120 \mathrm{~m}\end{array}$ & $\begin{array}{c}\text { B (day }+4), \\
3440 \mathrm{~m}\end{array}$ & $\begin{array}{c}\text { C (day }+14), \\
5050 \mathrm{~m}\end{array}$ \\
\hline $\begin{array}{l}\text { Ghrelin }(\mathrm{pg} / \mathrm{ml}) \\
\text { Females }\end{array}$ & $118 \pm 49$ & $116 \pm 54$ & $137 \pm 48$ \\
Males & $108 \pm 44$ & $120 \pm 59$ & $155 \pm 77^{\star}$ \\
GH $(\mu \mathrm{g} / \mathrm{l})$ & & & \\
Females & $3.4 \pm 4.4$ & $4.3 \pm 3.9$ & $5.3 \pm 3.7$ \\
Males & $0.7 \pm 1.0$ & $0.9 \pm 1.5$ & $2.6 \pm 3.1^{\star}$ \\
\hline
\end{tabular}

${ }^{\star} P<0.05 ;$ C vs A. 
role in acute metabolic adaptations and IGFBP2 regulating long-term bioavailability of IGFs. So far, no information on IGFBP1 and IGFBP2 during ascent to HA exists. Still, in analogy to HA, IGFBP1 upregulation by hypoxia, stress, and poor nutrient transfer has been demonstrated in fetuses with long-term chronic hypoxia and intrauterine growth restriction $(30,31)$. Similar mechanisms have been postulated to explain the even higher rise in IGFBP2 levels compared with IGFBP1 in placentas and cord blood from IUGR newborns, decreasing IGF bioavailability as an adaptive mechanism to shift energy resources from growth and development toward metabolic processes essential for survival (32). As insulin levels did not change in our probands, the increase in IGFBP1 and -2 at HA seems to have resulted from hypoxia and not from hypoinsulinism.

Our study has some limitations: first, the design restricted by environmental factors does not allow for a clear differentiation between effects resulting from hypoxia or from anorexia. Teleologically and what is known so far, physical exercise and hypoxia would stimulate hormonal responses to increase substrate supply, counteracted by energy-saving mechanisms provoked by HA-induced anorexia. Even though food intake according to dietary recall protocols was basically appropriate, adjustments to individual needs may occasionally have led to an inadequate caloric supply. Therefore, the influence of caloric variation on hormonal changes cannot be quantified, and the causative role of hypoxia needs to be interpreted with caution. For further insight, experimental studies, e.g. in a hypobaric hypoxic chamber providing controlled caloric consumption, would be desirable. Secondly, our ghrelin assay estimated total ghrelin levels without differentiation between biologically active acyl and desacyl ghrelin, which is the most abundant proghrelin peptide $(>90 \%)$ in plasma (33). Thirdly, single measurements do not accurately reflect pulsatile secretion of ghrelin and GH. However, serial blood investigations or provocative tests are practically not feasible in a large number of subjects under extreme conditions such as very HA.

As to further potentially confounding factors, effects from hypoxia on daily rhythms need to be considered. Hypoxia modifies the circadian oscillations of important variables such as body temperature and metabolic rate leading to perturbation of a variety of dependent other functions, e.g. sleep (34). It is well known that sleep architecture changes with altitude showing a decrease in slow wave sleep and an increase in incidents of periodic breathing (35). However, as in our study timepoint $\mathrm{C}$ investigations were performed after an acclimatization phase of 2 weeks at $\mathrm{HA}$ and subjective sleep quality was reported as acceptable, we assume that the adaptation process had already stabilized at the time of the critical investigation. In line with this, a circadian pattern of urinary melatonin excretion with markedly increased nocturnal levels at HA could be demonstrated (14). Given melatonin's key role in sleep regulation, its increase may have served to counterbalance the disturbed sleep-wake cycle at HA with a probable influence as a pacemaker on the control of many other circadian rhythms (36).

We did not have the opportunity to investigate leptin levels. Published data have been somewhat inconsistent reporting an increase $(12,37)$, a decrease $(38)$, or no change $(13,39)$ in leptin after ascent to HA. However, hypoxia has been shown to clearly increase leptin gene expression in adipocyte studies (40). As suggested by Zaccaria et al. (38), it therefore seems plausible that exposure to HA leads to a leptin increase, which causes a satiety signal to the brain contributing to anorexia and weight loss.

In conclusion, in our study that comprised the largest number of subjects investigated at very HA so far, we observed an increase in ghrelin and $\mathrm{GH}$ without a concomitant increase in GHBP, IGF1, IGF2, IGFBP3, and ALS levels after 2 weeks of exposure to very HA. IGFBP1 and IGFBP2 rose significantly, suggesting a change in IGF bioavailability. Our findings support the present concept of HA adaptation and are in accordance with the current knowledge on ghrelin and $\mathrm{GH}$ physiology.

\section{Declaration of interest}

The authors declare that there is no conflict of interest that could be perceived as prejudicing the impartiality of the research reported.

\section{Funding}

This work was supported by a grant from Pharmacia/Pfizer.

\section{Acknowledgements}

The authors thank Susanne Sagmeister for expert technical assistance. Furthermore, we are indebted to Karin Kral for evaluation of dietary protocols. The study was supported by the EV-K2-CNR Committee who allowed us to use the Pyramid Laboratory of the Italian Research Council at $5050 \mathrm{~m}$.

\section{References}

1 Gil-Campos M, Aguilera CM, Cañete R \& Gil A. Ghrelin: a hormone regulating food intake and energy homeostasis. British Journal of Nutrition 200696 201-226. (doi:10.1079/ BJN20061787)

2 Klok MD, Jakobsdottir S \& Drent ML. The role of leptin and ghrelin in the regulation of food intake and body weight in humans: a review. Obesity Reviews 20078 21-34. (doi:10.1111/j.1467789X.2006.00270.x)

3 Kamegai J, Tamura H, Shimizu T, Ishii S, Tatsuguchi A, Sugihara H, Oikawa S \& Kineman RD. The role of pituitary ghrelin in growth hormone $(\mathrm{GH})$ secretion: $\mathrm{GH}$-releasing hormone-dependent regulation of pituitary ghrelin gene expression and peptide content. Endocrinology 2004145 3731-3738. (doi:10.1210/en.20031424) 
4 Nass R, Farhy LS, Liu J, Prudom CE, Johnson ML, Veldhuis P, Pezzoli SS, Oliveri MC, Gaylinn BD, Geysen HM \& Thorner MO Evidence for acyl-ghrelin modulation of growth hormone release in the fed state. Journal of Clinical Endocrinology and Metabolism 200893 1988-1994. (doi:10.1210/jc.2007-2234)

5 Nguyen UN, Mougin F, Simon-Rigaud ML, Rouillon JD, Marguet P \& Regnard J. Influence of exercise duration on serum insulin-like growth factor and its binding proteins in athletes. European Journal of Applied Physiology 199878 533-537. (doi:10.1007/ s004210050456)

6 Koziris LP, Hickson RC, Chatterton RT, Groseth RT, Christie JM, Goldflies DG \& Unterman TG. Serum levels of total and free IGF-I and IGFBP-3 are increased and maintained in long-term training. Journal of Applied Physiology 199986 1436-1442.

7 Brown J, Jones EY \& Forbes BE. Keeping IGF-II under control: lessons from the IGF-II-IGF2R crystal structure. Trends in Biochemical Sciences 200934 612-619. (doi:10.1016/j.tibs. 2009.07.003)

8 Holt RIG, Simpson HL \& Sönksen PH. The role of the growth hormone-insulin-like growth factor axis in glucose homeostasis. Diabetic Medicine 200320 3-15. (doi:10.1046/j.1464-5491. 2003.00827.x)

9 Wheatcroft SB \& Kearney MT. IGF-dependent and IGF-independent actions of IGF-binding protein-1 and -2: implications for metabolic homeostasis. Trends in Endocrinology and Metabolism 200920 153-162. (doi:10.1016/j.tem.2009.01.002)

10 Popovici RM, Lu M, Bhatia S, Faessen GH, Giaccia AJ \& Giudice LC. Hypoxia regulates insulin-like growth factor-binding protein 1 in human fetal hepatocytes in primary culture: suggestive molecular mechanisms for in utero fetal growth restriction caused by uteroplacental insufficiency. Journal of Clinical Endocrinology and Metabolism 2001 86 2653-2659. (doi:10.1210/jc.86.6.2653)

11 Hamad N \& Travis SPL. Weight loss at high altitude: pathophysiology and practical implications. European Journal of Gastroenterology $\mathcal{E}$ Hepatology 200618 5-10. (doi:10.1097/00042737-20060100000002)

12 Shukla V, Singh SN, Vats P, Singh VK, Singh SB \& Banerjee PK. Ghrelin and leptin levels of sojourners and acclimatized lowlanders at high altitude. Nutritional Neuroscience $2005 \mathbf{8}$ 161-165. (doi:10.1080/10284150500132823)

13 Benso A, Broglio F, Aimaretti G, Lucatello B, Lanfranco F, Ghigo E \& Grottoli S. Endocrine and metabolic responses to extreme altitude and physical exercise in climbers. European Journal of Endocrinology 2007157 733-740. (doi:10.1530/EJE-07-0355)

14 Frisch H, Waldhauser F, Waldhör T, Müllner-Eidenböck A, Neupane P \& Schweitzer K. Increase in 6-hydroxymelatonin excretion in humans during ascent to high altitude. Journal of Clinical Endocrinology and Metabolism 200489 4388-4390. (doi:10.1210/jc.2003-032214)

15 Haditsch B, Roessler A \& Hinghofer-Szalkay HG. Renal adrenomedullin and high altitude diuresis. Physiological Research 2007 56 779-787.

16 Feddersen B, Ausserer H, Neupane P, Thanbichler F, Depaulis A, Waanders R \& Noachtar S. Right temporal cerebral dysfunction heralds symptoms of acute mountain sickness. Journal of Neurology 2007254 359-363. (doi:10.1007/s00415-006-0376-8)

17 Roach RC, Bartsch P, Oelz O \& Hackett PH \& the Lake Louise AMS Scoring Consensus Committee. The Lake Louise acute mountain sickness scoring system. In Hypoxia and Molecular Medicine, pp 272-274. Eds JR Sutton, CS Houston \& G Coates, Burlington, VT: Charles S. Houston, 1993.

18 Blum WF, Cotterill AM, Postel-Vinay MC, Ranke MB, Savage MO \& Wilton P. Improvement of diagnostic criteria in growth hormone insensitivity syndrome: solutions and pitfalls. Pharmacia Study Group on Insulin-like Growth Factor I Treatment in Growth Hormone Insensitivity Syndromes. Acta Paediatrica Supplement 1994399 117-124. (doi:10.1111/j.1651-2227. 1994.tb13303.x)

19 Blum WF \& Breier BH. Radioimmunoassays for IGFs and IGFBPs. Growth Regulation 19944 (Suppl 1) 11-19.
20 Natalucci G, Riedl S, Gleiss A, Zidek T \& Frisch H. Spontaneous 24-hour ghrelin secretion pattern in fasting subjects: maintenance of a meal-related pattern. European Journal of Endocrinology 2005152 845-850. (doi:10.1530/eje.1.01919)

21 Kleinz MJ, Maguire JJ, Skepper JN \& Davenport AP. Functional and immunocytochemical evidence for a role of ghrelin and des-octanoyl ghrelin in the regulation of vascular tone in man. Cardiovascular Research $2006 \quad 69$ 227-235. (doi:10.1016/ j.cardiores.2005.09.001)

22 Schwenke DO, Tokudome T, Shirai M, Hosoda H, Horio T, Kishimoto I \& Kangawa K. Exogenous ghrelin attenuates the progression of chronic hypoxia-induced pulmonary hypertension in conscious rats. Endocrinology 2008149 237-244. (doi:10.1210/en.2007-0833)

23 Schwenke DO, Tokudome T, Kishimoto I, Horio T, Shirai M, Cragg PA \& Kangawa K. Early ghrelin treatment following myocardial infarction prevents an increase in cardiac sympathetic tone and reduces mortality. Endocrinology 2008149 5172-5176. (doi:10.1210/en.2008-0472)

24 Lippl FJ, Neubauer S, Schipfer S, Lichter N, Tufman A, Otto B \& Fischer R. Hypobaric hypoxia causes body weight reduction in obese subjects. Obesity 201018 675-681. (doi:10.1038/oby. 2009.509)

25 Banfi G, Marinelli M, Roi GS, Columbini A, Potillo M, Giacometti M \& Wade S. Growth hormone and insulin-like growth factor I in athletes performing a marathon at $4000 \mathrm{~m}$ of altitude. Growth Regulation 19944 82-86.

26 Ramirez G, Herrerat R, Pineda D, Bittle P, Rabb H \& Bercus B. The effects of high altitude on hypothalamic-pituitary secretory dynamics in men. Clinical Endocrinology 199543 11-18. (doi:10.1111/j.1365-2265.1995.tb01887.x)

27 Schmidt W, Dore S, Hilgendorf A, Strauch S, Gareau R \& Brisson GR. Effects of exercise during normoxia and hypoxia on the growth hormone-insulin-like growth factor I axis. European Journal of Applied Physiology 199571 424-430. (doi:10.1007/ BF00635876)

28 Greenman Y, Golani N, Gilad S, Yaron M, Limor R \& Stern N. Ghrelin secretion is modulated in a nutrient and gender specific manner. Clinical Endocrinology 200460 382-388. (doi:10.1111/ j.1365-2265.2004.01993.x)

29 Frystyk J, Andreasen CM \& Fisker S. Determination of free growth hormone. Journal of Clinical Endocrinology and Metabolism 2008 93 3008-3014. (doi:10.1210/jc.2008-0375)

30 Tapanainen PJ, Bang P, Wilson K, Unterman TG, Vreman HJ \& Rosenfeld RG. Maternal hypoxia as a model for intrauterine growth retardation: effects on insulin-like growth factors and their binding proteins. Pediatric Research 199436 152-158. (doi:10.1203/00006450-199408000-00004)

31 Verhaeghe J, van Herck E, Billen J, Moerman P, van Assche FA \& Giudice LC. Regulation of insulin-like growth factor-I and Insulinlike growth factor binding protein-1 concentration in preterm fetuses. American Journal of Obstetrics and Gynecology $2003 \mathbf{1 8 8}$ 485-491. (doi:10.1067/mob.2003.26)

32 Street ME, Seghini P, Fieni S, Ziveri MA, Volta C, Martorana D, Viani I, Gramellini D \& Bernasconi S. Changes in interleukin-6 and IGF system and their relationships in placenta and cord blood in newborns with fetal growth restriction compared with controls. European Journal of Endocrinology 2006155 567-574. (doi:10.1530/eje.1.02251)

33 Bang AS, Soule SG, Yandle TG, Richards AM \& Pemberton CJ. Characterisation of proghrelin in mammalian tissue and plasma. Journal of Endocrinology 2007192 313-323. (doi:10.1677/JOE06-0021)

34 Mortola JP. Hypoxia and circadian patterns. Respiratory Physiology $\mathcal{E}$ Neurobiology 2007158 274-279. (doi:10.1016/j.resp.2007. 02.005)

35 Johnson PL, Edwards N, Burgess KR \& Sullivan CE. Sleep architecture changes during a trek from 1400 to $5000 \mathrm{~m}$ in the Nepal Himalaya. Journal of Sleep Research 201019 148-156. (doi:10.1111/j.1365-2869.2009.00745.x) 
36 Arendt J. Importance and relevance of melatonin to human biological rhythms. Journal of Neuroendocrinology 200315 427-431. (doi:10.1046/j.1365-2826.2003.00987.x)

37 Tschöp M, Strasburger CJ, Hartmann G, Biollaz J \& Bärtsch P. Raised leptin concentrations at high altitude associated with loss of appetite. Lancet 1998352 1119-1120. (doi:10.1016/S01406736(05)79760-9)

38 Zaccaria M, Ermolao A, Bonvicini P, Travain G \& Varnier M. Decreased serum leptin levels during prolonged high altitude exposure. European Journal of Applied Physiology 200492 249-253. (doi:10.1007/s00421-004-1070-0)

39 Barnholt KE, Hoffman AR, Rock PB, Muza SR, Fulco CS, Braun B, Holloway L, Mazzeo RS, Cymerman A \& Friedlander AL. Endocrine responses to acute and chronic high-altitude exposure $(4,300$ meters): modulating effects of caloric restriction. American Journal of Physiology. Endocrinology and Metabolism 2006290 E1078-E1088. (doi:10.1152/ajpendo.00449.2005)

40 Grosfeld A, Zilberfarb V, Turban S, André J, Guerre-Millo M \& Issad T. Hypoxia increases leptin expression in human PAZ6 adipose cells. Diabetologia $2002 \mathbf{4 5} 527-530$. (doi:10.1007/ s00125-002-0804-y)

Received 30 July 2011

Revised version received 8 March 2012

Accepted 12 March 2012 